\title{
Dynamic characteristics analysis of hydraulic pipes on anti-rolling Suspension system
}

\author{
Hou YouShan ${ }^{1, a}$, Song HuiXin ${ }^{1, a}$,Chen $\mathrm{Yu}^{1, \mathrm{~b}}$, Yao LingYu ${ }^{1, \mathrm{a}}$ \\ ${ }^{1}$ Chinese north vehicle research institute, Beijing, china, 100072 \\ a13501152440@126.com, b chenyu_beijing@139.com,
}

Keywords: hydraulic pipes; bond graph; anti-rolling;suspension; dynamic characteristics

\begin{abstract}
Based on power bond graph-block diagram method, the general mathematical models of the suspension cylinder, hydraulic pipes and accumulator are established, and the simulation model is established based on SIMULINK control simulation software. A heavy-duty anti-rolling suspension system is used as a study object, quantitative analyzing the dynamic characteristics response of hydraulic pipes on heavy-duty anti-rolling suspension system under different frequency.The results show that the hydraulic pipes' inertia effect, flow resistance losses and pipe wall elasticity have great impact on the dynamic performance of hydraulic system, especially the high frequency servo hydraulic system.
\end{abstract}

\section{Introduction}

Heavy-duty anti-rolling suspension system is used to suppress rolling trend and improve the driving safety while driving, A heavy-duty truck anti-rolling suspension system with poor running smoothness is due to the smaller size of the pipe between the external accumulator and cylinder.Hydraulic pipe is the important component of the heavy-duty anti-rolling suspension system, the hydraulic pipes' inertia effect, flow resistance losses and pipe wall elasticity have great impact on the dynamic performance of hydraulic system, especially the high frequency servo hydraulic system. Many papers in establishing the hydraulic system models usually ignore or simplify the influence of hydraulic pipes on hydraulic system.In fact, the influence of hydraulic pipes parameters on hydraulic system, especially the high frequency servo hydraulic system dynamic response should not be ignored.

Pipes have capacitive,resistive and sentimental effects which are distributed on the entire road。 At present, the main research methods on dynamic characteristics of pipes are method of characteristics, frequency method $^{[1]}$, distributed-parameters bond graph method ${ }^{[2-3]}$ and so on 。 Sectional lumped parameter method is one of the frequency method, which is suitable when the pipeline is short, the frequency pulse is low, or a larger error occurs; For the high-precision processing on the friction, the recursive algorithm of the method of characteristics is regular and accurate, but for the boundary value problems and the difficulties in connecting to related fluid component models, the method of characteristics used in practical engineering is limited ${ }^{[4]}$; Distributed-parameters method is one of another frequency method, which is accurate in studying pipes。

This paper uses lumped parameter pipeline impedance with limited number to replace Distributed-parameter pipeline impedance approximately and the sectional lumped parameter method which simplifies the transfer matrix to create bond graph model of hydraulic pipeline, simultaneously, referring to method including dynamic friction put forward by LI Hong-ren and CHENG Zhao-di ${ }^{[5]}$, it amends the sectional lumped parameter model。

In this paper, a heavy-duty truck anti-rolling suspension system with external accumulator is studied as an object, studying the hydraulic pipe parameters between the cylinder and the accumulator influence on the dynamic characteristics of the anti-rolling suspension system, the 
physical model of the anti-rolling suspension system,including pipes model is established based on power bond graph-block digram modeling throry, the dynamic simulation model is set up using SIMULINK,mainly studying the influence of pipe parameters between cylinder and accumulator on dynamic characteristic of the anti-rolling suspension system ${ }^{[6]}$.

\section{Physical and Simulation Model}

Heavy-duty anti-rolling suspension system is a nonlinear system, the physical model can be simplified an equivalent dynamic model as shown in figure 1 , the equivalent model compses of cylinder, accumulator, hydraulic pipe, equivalent resistance components and sprung mass, etc.

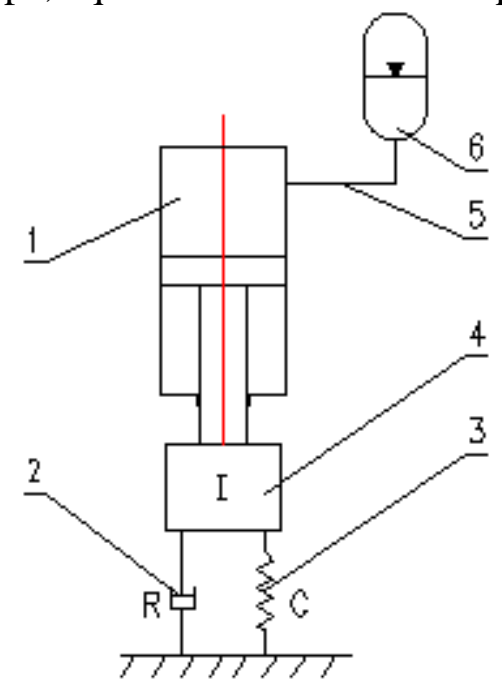

Fig.1 Simplified model of anti-rolling suspension system

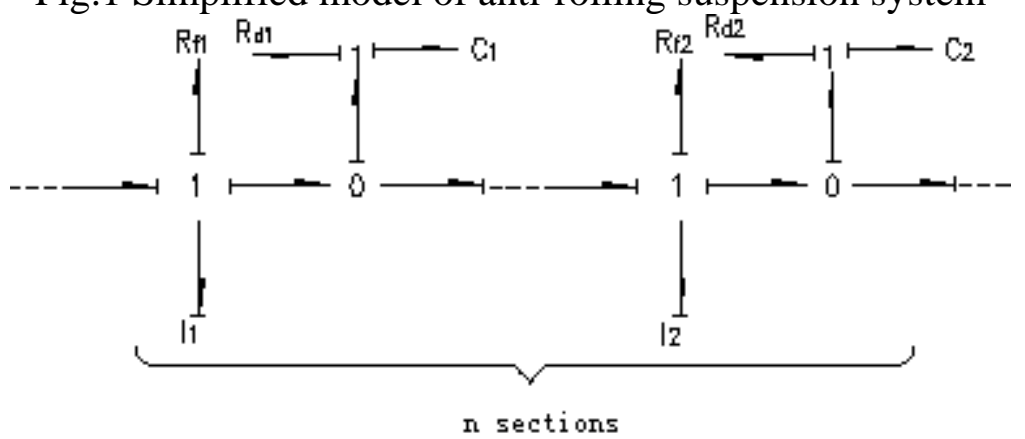

Fig. $2 \mathrm{~N}$ section bond graph model of hydraulic pipe

The diagram 2 is the bond graph model of pipe divided into $\mathrm{N}$ segments.

$R_{f 1} / R_{f 2}$ - static friction fluid resistance, $N \cdot s \cdot m^{-5}$ 。General expression $R_{f}=\frac{128 \rho v l}{\pi d^{4}}(\rho$-fluid density, $\mathrm{kg} \cdot \mathrm{m}^{-3} ; \quad v$-fluid movement viscosity, $\mathrm{m}^{2} / \mathrm{s} ; \boldsymbol{l}$-pipe length, $m ; d$-pipe diameter, $m$ ) ; $R_{d 1} / R_{d 2}$ - dynamic friction fluid resistance, $N \cdot s \cdot m^{-5}$ 。 General expression $R_{d}=1304.987(\mathrm{l} / \mathrm{r})^{-0.6392} R_{f} ; \quad I_{1} / I_{2}$-fluid sense, $\mathrm{kg} \cdot \mathrm{m}^{-4}$ 。 Linear expression $I=\frac{\rho l}{A}(\rho$-fluid density, $\mathrm{kg} \cdot \mathrm{m}^{-3} ; l$-pipe length, $m ; A$-pipe cross-sectional area, $\left.\mathrm{m}^{2}\right) ; C_{1} / C_{2}$-fluid capacity, $m^{5} \cdot N^{-1}$ 。Linear expression $C=\pi r_{0}^{2} l\left(\frac{1}{E_{w}}+\frac{1}{K_{f}}\right)\left(E_{w}\right.$-pipe volume elastic modulus, $P a ; K_{f}$-fluid volume elastic modulus, $\mathrm{Pa}$ ).

The simulink simulation model is shown in figure 3. 


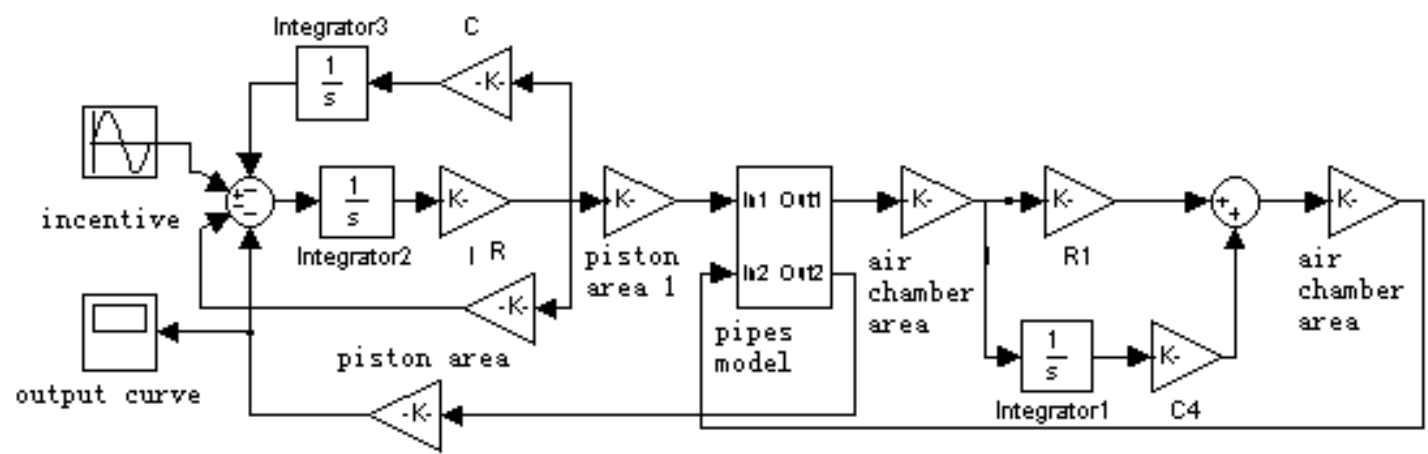

Fig.3 Schematic of SIMULINK simulation model

\section{The Instance Simulation Analysis}

In order to quantitatively analyze the influence of pipe parameters change on the high frequency response characteristics of anti-rolling suspension system, simulating the dynamic performance of anti-rolling suspension system by inputing pulse signal to the simulation model. According to the actual situation of hydraulic pipes, the hydraulic pipe is divided into three units to simulate, the related technical parameters of a heavy-duty anti-rolling suspension system are shown in table 1.

Table 1 Related Technical Parameters of Anti-rolling suspension system

\begin{tabular}{ccccccc}
\hline parameter & $\begin{array}{c}\text { Piston } \\
\text { diameter(m) }\end{array}$ & $\begin{array}{c}\text { Oil density } \\
\left(\mathrm{kg} / \mathrm{m}^{3}\right)\end{array}$ & $\begin{array}{c}\text { Kinematic } \\
\text { viscosity } \\
\left(\mathrm{m}^{2} / \mathrm{s}\right)\end{array}$ & $\begin{array}{c}\text { elasticity } \\
\text { Modulus } \\
(\mathrm{Pa})\end{array}$ & $\begin{array}{c}\text { Vibration } \\
\text { amplitude } \\
(\mathrm{m})\end{array}$ & $\begin{array}{c}\text { Air } \\
\text { chamber } \\
\text { diameter(m) }\end{array}$ \\
\hline value & 0.14 & 880 & $5 \times 10^{-5}$ & $7.0 \times 10^{8}$ & 0.05 & 0.1 \\
\hline parameter & $\begin{array}{c}\text { Suspension } \\
\text { Frequency } \\
(\mathrm{Hz})\end{array}$ & $\begin{array}{c}\text { Coefficient } \\
(\mathrm{N} / \mathrm{m})\end{array}$ & $\begin{array}{c}\text { Damping } \\
\text { coefficient } \\
(\mathrm{N} \cdot \mathrm{s} / \mathrm{m})\end{array}$ & $\begin{array}{c}\text { Pipe } \\
\text { Diameter } \\
(\mathrm{mm})\end{array}$ & $\begin{array}{c}\text { Pipe } \\
\text { length(m) }\end{array}$ & $\begin{array}{c}\text { Elamber } \\
\text { chacity } \\
\text { Coefficient } \\
(\mathrm{m} / \mathrm{N})\end{array}$ \\
\hline value & 1 & 0 & $1.6 \times 10^{4}$ & 30 & 1 & $1.6 \times 10^{4}$ \\
\hline
\end{tabular}

Taking the parameters in table 1 into simulation model shown in figure 3 , the simulation results are shown in figure 4. As can be seen from the figure 5: $1 \mathrm{HZ}$ excitation signal is applied on piston rod, the cylinder pressure of non-rod cavity has a big drastic fluctuation process, instantaneous peak pressure reaches around $5.85 \mathrm{Mpa}$, after about $0.35 \mathrm{~s}$, the system pressure fluctuations eliminate.

The vibrator frequency $0.33 \mathrm{HZ}, 1 \mathrm{HZ}, 2 \mathrm{HZ}$ are applied on the piston rod respectively, the pressure changes in the non-rod cavity of cylinder are shown in figure 5.

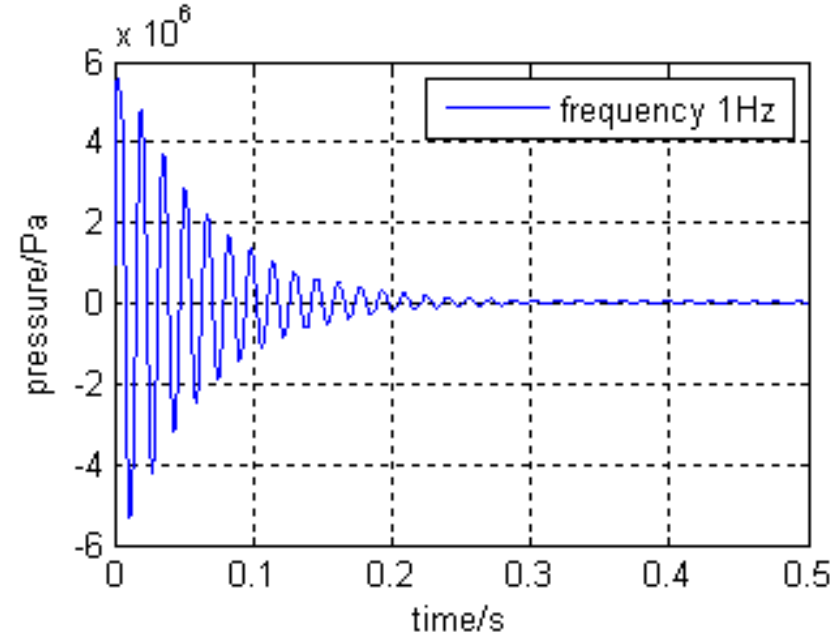

Fig.4 Simulation result(I)

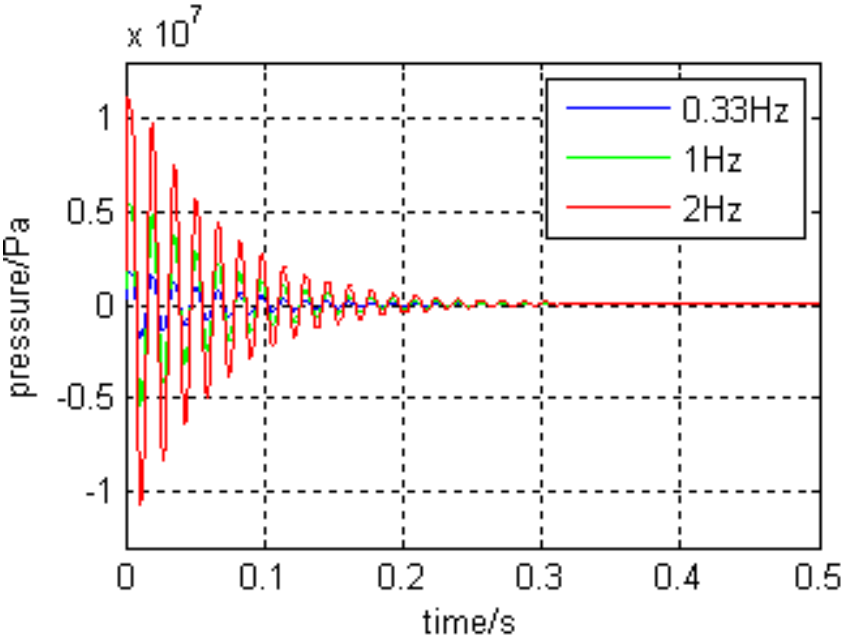

Fig.5 Simulation result(II) 


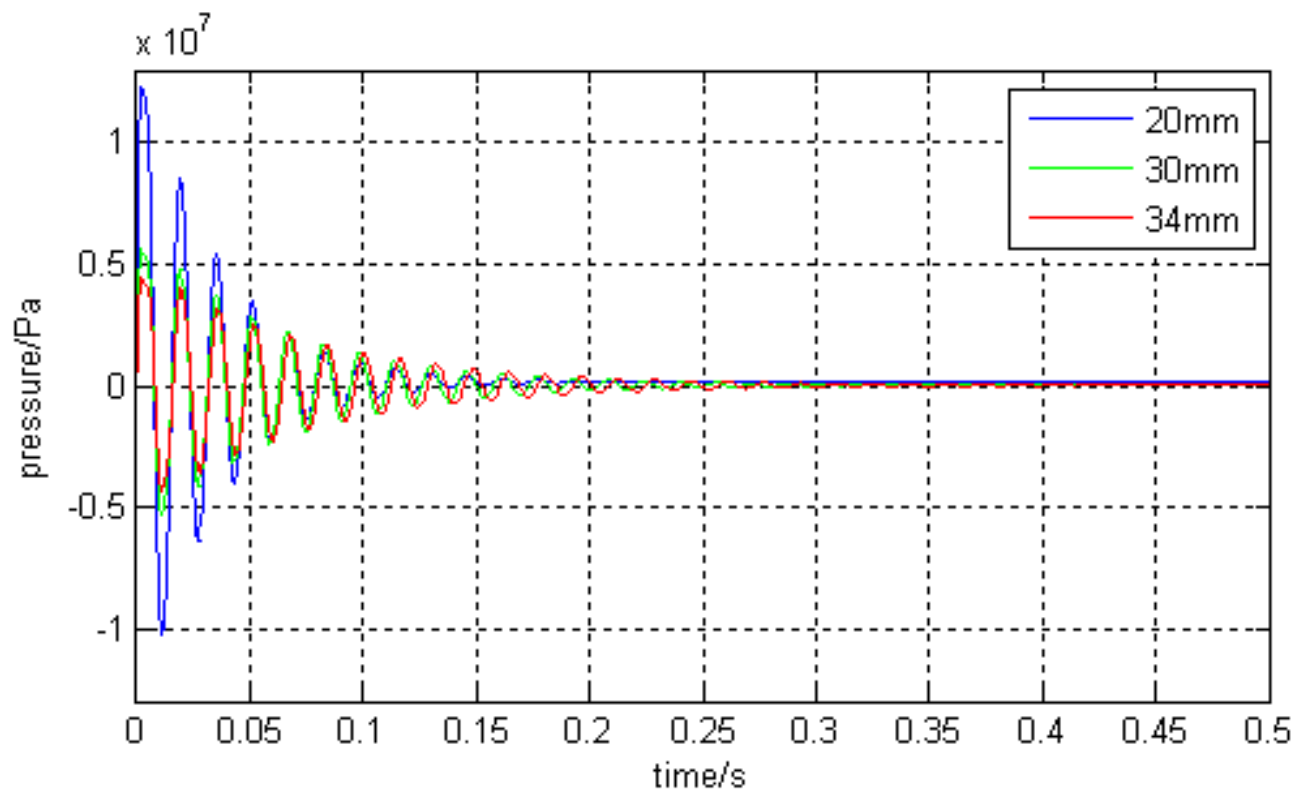

Fig.6 Simulation result(III)

As can be seen from Fig.5, under the frequency 0.33HZ, the instaneous peak pressure of cylinder non-rod cavity is $2 \mathrm{Mpa}$; under the frequency $1 \mathrm{HZ}$, the instaneous peak pressure of cylinder non-rod cavity is 5.8Mpa; under the frequency $2 \mathrm{HZ}$, the instaneous peak pressure of cylinder non-rod cavity is $12 \mathrm{Mpa}$. The simulation results show that with the increasement of excitation vibration frequency, the fluctuation peak pressure increases respectively, the running smoothness get bad too.

As can be seen from Fig.6, under the frequency 0.33HZ, while the pipe diameter is $20 \mathrm{~mm}$, the instaneous peak pressure of cylinder non-rod cavity reaches $14 \mathrm{Mpa}$ immediately; while the pipe diameter is $30 \mathrm{~mm}$, the instaneous peak pressure of cylinder non-rod cavity reaches $5.8 \mathrm{Mpa}$ immediately; while the pipe diameter is $34 \mathrm{~mm}$, the instaneous peak pressure of cylinder non-rod cavity reaches $4.5 \mathrm{Mpa}$ immediately. The simulation results show that with the increasement of pipe diameter, the fluctuation peak pressure increases respectively, the running smoothness improves betterly. The pipe parameters greatly influence the dynamic performance of anti-rolling suspension system, it is important to design the pipe diameter.

\section{Conclusion}

Based on the bond graph-block diagram, the mathematical and simulation model of hydraulic pipe of anti-rolling suspension system is established, the model takes into account the kinetic friction factor and analyzes the impact of the pipe on the anti-rolling suspension system performance 。 The simulation results show that the hydraulic pipe parameters have great impacts on the dynamic characteristics of anti-rolling suspension system and should not be ignored。

The mathematical model established basing on the bond graph theory and simulink is universal, it provides a theory method for parametric design。

\section{Reference:}

[1] asaaki Senga.Modeling and analysis of power steering system[D].Massachusetts:Massachusetts Institute of Technology,1995.

[2] Margolis D L.Yang W C.Bond graph models for fluid networks using model approximation.Journal of Dynamic System,Measurement and Control,1985,107(9):169-175.

[3] Li Hong ren,Chen Zhao di .New sectional concentrated parameter rmodel using bond graphs for hydraulic pipelines[J].China Journal of Mechanical Engineering,2000,36(3):61 64. (in Chinese). 
[4] WANG Zhong-shuang. Bond Graph Theory and Its Application of System Dynamics[M].HaErBin: Harbin Engineering University Press,2000.

[5] PAN Ya-dong. Introduction to bond graphs------A system dynamic method[M].ChongQing: Chongqing University Press,1991.

[6] Hou Youshan, Shi Boqiang, Xiao Chenyong Dynamic characteristics study on hydraulic pipelines of steering system of articulated vehicles[J]。 Transaction of the CSAE, 2009,25(10): 1-4.(in chinese) 